\title{
Application of three-dimensional technologies in restoration of architectural decor elements
}

\author{
Veniamin Norin $^{1 *}$, Svetlana Golovina ${ }^{1}$, and Yurii Tikhonov ${ }^{1}$ \\ ${ }^{1}$ Saint Petersburg State University of Architecture and Civil Engineering, 190005, 2nd \\ Krasnoarmeyskaya St., 4, St. Petersburg, Russia
}

\begin{abstract}
The article deals with issues of applying modern innovative three-dimensional techniques in production and restoration of facade decor elements. Methodology for producing an exact physical copy of a part under restoration is set forth as exemplified by the architectural rosette. It details a methodology of how to conduct virtual digital restoration of a rosette using one of the best software solutions for digital molding, Zbrush, which is a superb tool to create high-definition three-dimensional objects. Two methods of digital restoration are treated: copying and sculpting. The copying method produces the geometric shape of an article consisting of items with identical dimensions. Sculpting is performed using digital molding, i.e. working with digital clay - a more intuitive modeling method compared to traditional techniques. Possible methods of production of the restored physical copy of a damaged rosette, their merits, and demerits are described. The study provides a forecast for development of architectural monument restoration with the use of three-dimensional techniques.
\end{abstract}

\section{Introduction}

Historic buildings of Saint Petersburg are the buildings that are landmarked, protected by UNESCO and regulated by the Committee for the State Inspection and Protection of Historic and Cultural Monuments (KGIOP). They are of historical significance and, therefore, must preserve their pristine historical appearance after reconstruction or restoration. Some buildings in the city center have, for the most part, undergone no overhaul or restoration in 100 years. Those buildings (architectural landmarks) call for a special approach. Issues are mostly related to low-quality facade restoration. The shapes of decorative architectural elements like reliefs and bas-reliefs become deformed; those are often impossible to restore to their initial shape. There is a fair amount of good examples of the like: item features are deformed, superfluous motif elements are added, and initial forms get a completely different appearance and size after restoration.

At present, restoration of historical building facades more often than ever uses innovative 3D scanning and printing techniques, which produce an exact digital threedimensional copy of an object within minutes. Application of the three-dimensional

\footnotetext{
* Corresponding author: norinveniamin@ yandex.ru
} 
scanning technology produces high accuracy of digital copies of the elements scanned [16], enables repeated reproduction of undistorted architectural items and parts, and makes it possible to produce shallow (lightweight) and solid elements of exterior and interior decor

The advantage of 3D scanning as compared with other methods of measuring historical and cultural heritage sites [7] is evident because it allows obtaining an excessive array of points with three-dimensional coordinates in a short time frame. This array of points represents a precise model of an item, forming a "cloud" of 3D coordinates. The point cloud contains complete item data that may be used any time to obtain additional information without having to measure any extra on-site fields. Besides, a digital copy is simpler to store in computer memory, i. e. it will always be possible to restore a damaged item.

Besides, 3D scanning may be used to measure items in places that are hard to access and in dark places $[8,9]$, thus restoring a detailed geometry and surface of the scanned item. It should be highlighted that $3 \mathrm{D}$ scanning is on high demand when it comes to measuring item parts with complicated geometry, curved surfaces, decorative elements, and sculptural compositions [10] because, during the preparation of measurement drawings, a general layout of the item is required in several projections. Only $3 \mathrm{D}$ scanning can provide complete data on the field measurements.

It should be noted that there currently are no universal ways to restore architectural decor elements using $3 \mathrm{D}$ techniques as every element to be restored is unique. The public media has considered the issues of preserving cultural heritage digitally quite well [11-19]. However, the issues related to digital restoration of architectural decor items using a powerful software like Zbrush have not been researched well enough, which is the topic of this paper.

\section{Methods}

The restoration methodology for architectural decor elements is discussed as exemplified by the architectural rosette (Fig. 1a). The photo clearly shows the defects on three chipped petals of the rosette.

Restoration of the damaged architectural decor element using 3D scanning and printing can be divided into 3 stages.

1. Scanning the damaged part and producing an exact digital copy of the part to be restored.

2. Editing the digital model.

3. Production of the original shape of the part under restoration.

The first stage included scanning the architectural decor elements. To do that, an optic hand-held scanner, Artec Eva, was used. The choice of the scanning device was made based on a comparative analysis of technical features of 3D scanners used to scan architectural decor elements (Table 1). In this case, the scanning precision was up to $0.1 \mathrm{~mm}$. That precision of scanning with Artec Eva was perfect in terms of cost efficiency for the restoration of architectural decor elements (bas-reliefs, consoles, column caps, etc.), monuments, plasterworks, etc.

Being an optic 3D scanner, Artec Eva is a light mobile device based on the projection of interferential stripes, which ensures precise and traceable 3D coordinates, and high scanning rate. Its application excludes any distortion, even in cases when the scanned item is moving. The improved system of surface tracing ensures precise scanning of the data and does not require installation of markers, which saves operation time significantly. 
The process of scanning that includes two stages (field and cameral works) is described in detail in the article [20]. The data processing was performed with Artec Studio 13. The result of the first stage of scanning was a precise digital copy of the restored rosette (Fig. 1b).

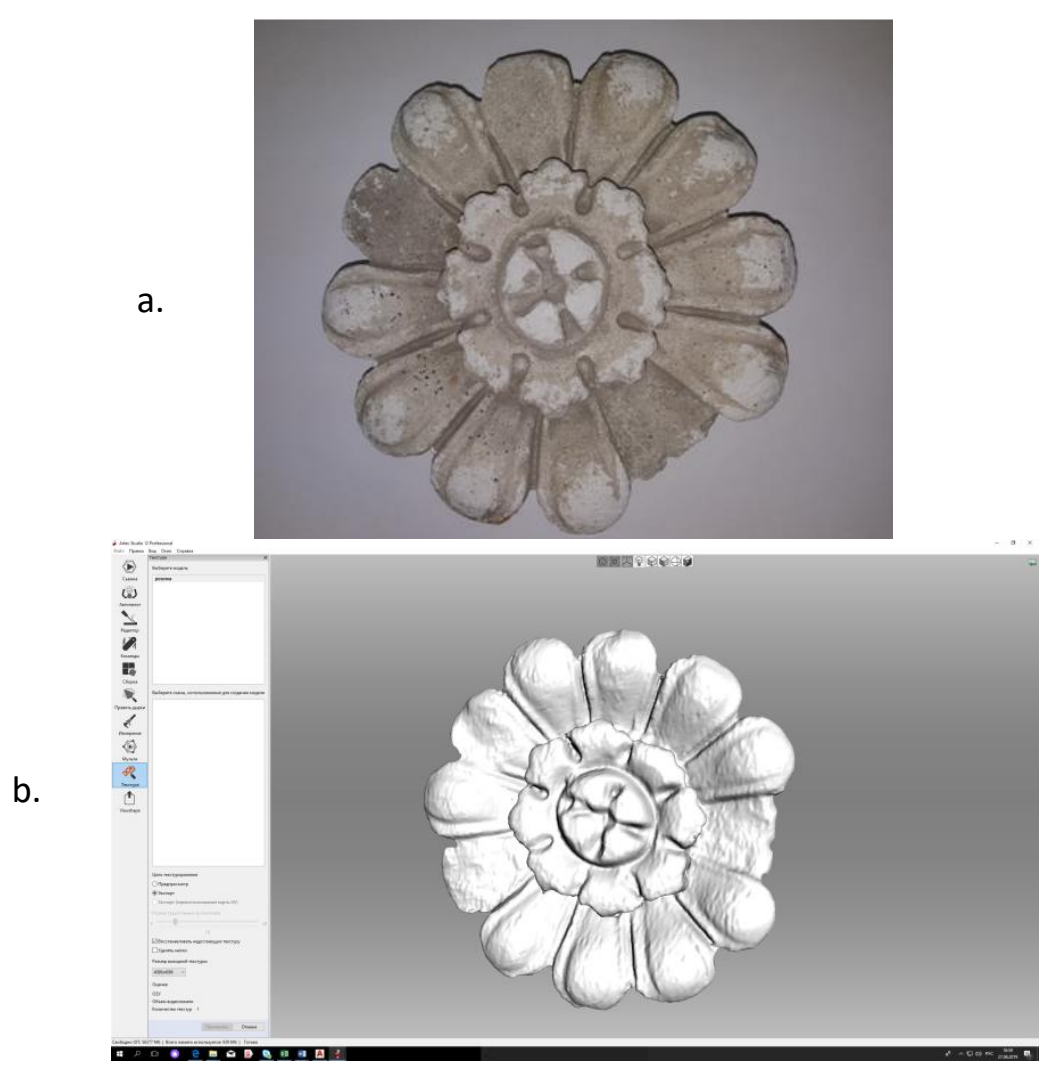

Fig. 1. $a$ - photo of a plaster rosette with the defects; $b$ - a precise digital copy of the restored rosette.

The second stage is editing the digital model. This stage is, in fact, the very "restoration" of the damaged part, except this is not restoration of the actual solid-state plaster part, but virtual restoration, i.e. restoration of the original shape in a digital copy of the damaged part. This stage of restoration, like in case of conventional restoration technology, presents the biggest challenge.

Stage three. Methods of production of a part under restoration are determined by factors like dimensions, required restoration dates, properties of the part's material, and economic feasibility.

To put virtual restoration into practice, as the authors believe, it might be advisable to use one of the best software solutions for digital molding, Zbrush by Pixologic, which is a superb tool to create high-definition three-dimensional objects.

Factually, the 3D object does not exist. In reality, professionals always have to work with a $2 \mathrm{D}$ screen image of the $3 \mathrm{D}$ object or, to be more precise, with an image of the 3D object we see on the monitor's screen. This is what we mean when we speak of a virtual 3D object.

A virtual object in a $3 \mathrm{D}$ space consists of polygons. A polygon is a geometric figure defined by three or more points called polygonal peaks. In Zbrush, polygons are presented 
as figures with three or four apexes. Sets of adjoining polygons form the surface of 3D objects. The number of such polygons can reach several million. Operating the polygons allows for surface deformation. As a rule, polygonal modeling is considered hollow modeling, wherein the object is represented only by its surface.

Table 1. Features of 3D scanners.

\begin{tabular}{|c|c|c|c|c|}
\hline Description & $\begin{array}{l}\text { Scanning } \\
\text { technology }\end{array}$ & Light source & $\begin{array}{c}\text { Scanning } \\
\text { precision, } \mathrm{mm}\end{array}$ & $\begin{array}{l}\text { Operating } \\
\text { distance to } \\
\text { the item, } m\end{array}$ \\
\hline Artec Eva & Optical & Photoflash & up to 0.1 & $0.4-1$ \\
\hline Artec Eva Lite & Optical & Photoflash & up to 0.2 & $0.4-1$ \\
\hline Artec Spider & Optical & Blue LED & up to 0.3 & $0.17-0.35$ \\
\hline Artec Space Spider & Optical & Blue LED & up to 0.03 & $0.17-0.35$ \\
\hline $\begin{array}{c}\text { RangeVision Smart } \\
\text { (stationary) }\end{array}$ & Optical & LED & up to 0.1 & up to 1 \\
\hline $\begin{array}{c}\text { RangeVision Standart } \\
\text { Plus } \\
\text { (stationary) } \\
\end{array}$ & Optical & Halogen lamp & $0.03-0.16$ & $0.27-1.1$ \\
\hline $\begin{array}{c}\text { RangeVision } \\
\text { Advanced } \\
\text { (stationary) }\end{array}$ & Optical & Halogen lamp & $0.03-0.16$ & $0.27-1.1$ \\
\hline $\begin{array}{c}\text { Creaform Go!SCAN } \\
20\end{array}$ & Optical & LED & up to 0.1 & up to 0.38 \\
\hline $\begin{array}{c}\text { Creaform Go!SCAN } \\
50\end{array}$ & Optical & White LED & up to 0.1 & up to 0.4 \\
\hline $\begin{array}{c}\text { Solutionix Rexcan } 4 \\
\text { (stationary) }\end{array}$ & Optical & LED & $0.03-0.71$ & $0.43-1.33$ \\
\hline $\begin{array}{c}\text { Solutionix Rexcan } \\
\text { CS+ } \\
\text { (stationary) }\end{array}$ & Optical & LED & up to 0.01 & auto \\
\hline $\begin{array}{c}\text { GOM ATOS Core } 45 \\
\text { (stationary) }\end{array}$ & Optical & Blue LED & up to 0.02 & up to 0.17 \\
\hline $\begin{array}{c}\text { GOM ATO Core } 135 \\
\text { (stationary) }\end{array}$ & Optical & Blue LED & up to 0.05 & up to 0.17 \\
\hline Sense Next Gen & Laser & - & $0.5-0.9$ & up to 1.6 \\
\hline EinScan Pro & Optical & White LED & up to 0,3 & up to 0,51 \\
\hline $\begin{array}{c}\text { Creaform HandySCAN } \\
700 \\
\end{array}$ & Laser & - & up to 0,03 & up to 0,3 \\
\hline
\end{tabular}




\begin{tabular}{|l|l|l|l|c|}
\hline FARO Freestyle 3D & Laser & - & up to 1 & $0,5-3$ \\
\hline
\end{tabular}

\section{Results and discussion}

Digital restoration begins once a file with the virtual copy of the rosette has been uploaded into Zbrush. The original shape of the petals chipped on the front (Fig. 2a) and back (Fig.2b) sides can be restored using the so-called digital molding.

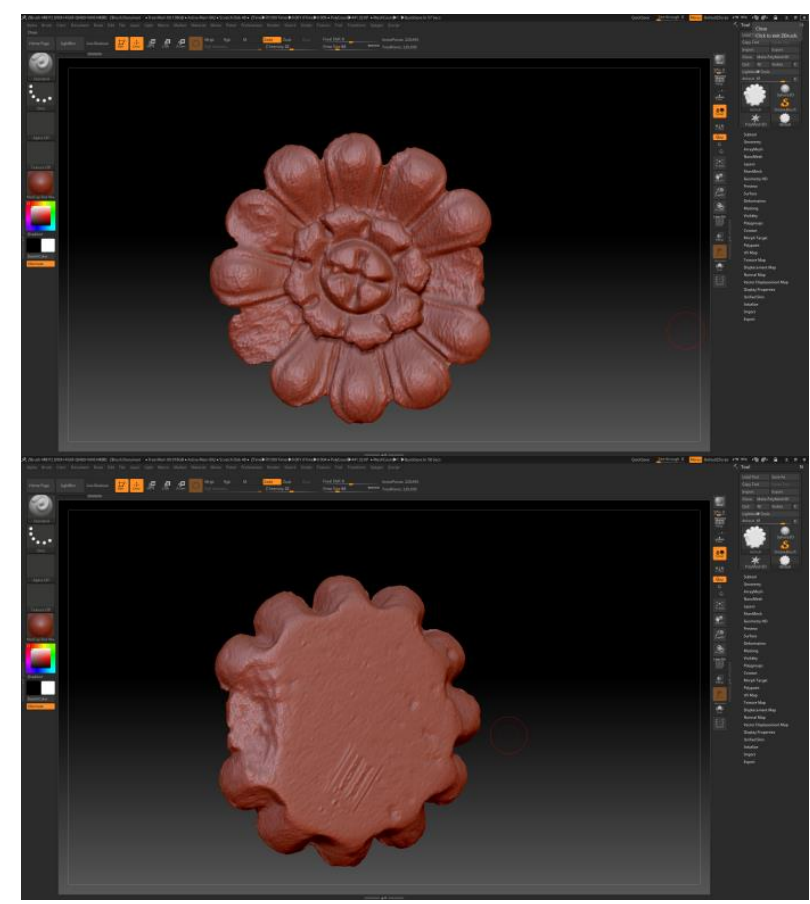

Fig. 2. Digital copy of a rosette in Zbrush ( $\mathrm{a}$ - front side, $\mathrm{b}$ - reverse size).

Digital molding is a technique of 3D modeling using specialized brushes. This innovative technology was first proposed by the creators of Zbrush. The known ways of creating and editing three-dimensional objects based on manipulations with single polygons and vertexes have made way for work with digital clay, i.e. a more intuitive method of modeling as compared to previous techniques. The term 'digital clay' in Zbrush means a polygonal mesh, i. e. a mesh consisting of a multitude of adjoining facets. The vertexes and edges of each facet or polygon simultaneously belong to other adjacent facets. Desired shape is done using the so-called specialized sculpting brushes; this process resembles working with a real clay. Therefore, those meshes are called "digital clay".

First, the "clay mass" is built up on the chipped surfaces of the rosette (Fig. 3). 
a.

b.

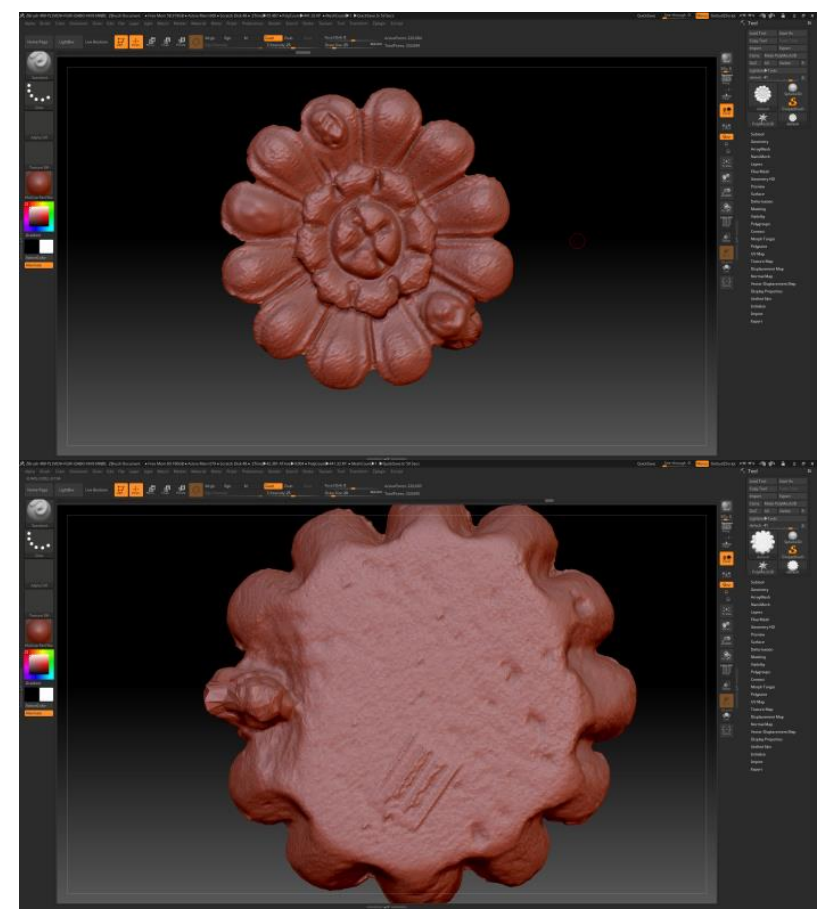

Fig. 3. A buildup of "clay mass" on the rosette chip ( $\mathrm{a}$ - front side, $\mathrm{b}$ - reverse side).

Then the "clay" is spread on the entire surface of the chipped petal. The next step is to shape the petal into its original form and "smooth out" the resulting surface (Fig. 4). If necessary, refinement of the polygonal mesh can be increased with mesh tessellation.

However, in if the shape of digital model consists of repeated identical elements, the restoration method described above is inadvisable because creating two or more elements of identical shape and size manually is a rather labour-intensive process. Each of those elements will somehow differ from others. For that reason, it may be advisable to use copying to restore the product's original shape. The advantage of this method is that it produces the shape made up by elements with identical dimensions.

Analysis of the geometrical shape of the rosette revealed that it has rotational symmetry of order 4. In this context, the target element is selected on the rosette, whose rotation about the Z-axis through $360^{\circ} / \mathrm{n}(\mathrm{n}=4)$ produces the desired rosette shape. The selected element (the basic element) must not contain chipped petals. It should be fashioned as a separate polygroup (Fig. 5) and left on the canvas (in the display space) with everything else removed using the Modify Topology tool.

Then the selected polygroup should be duplicated, with the lateral surfaces of the selected element closed beforehand to prevent issues with shaping the geometry of the form in production. The Rotate tool is used to define the center of rotation of the basic element, and it is rotated about the $\mathrm{Z}$-axis through $90^{\circ}$. At the next stage, the Merge Down tool is used to merge two elements into one polygroup that represents a half of the rosette (Fig. 6).

Then it is advisable to use the symmetry tool Mirrorandweld to mirror the unified polygroup. These two actions result in the complete rosette shape (Fig. 7). 
a.

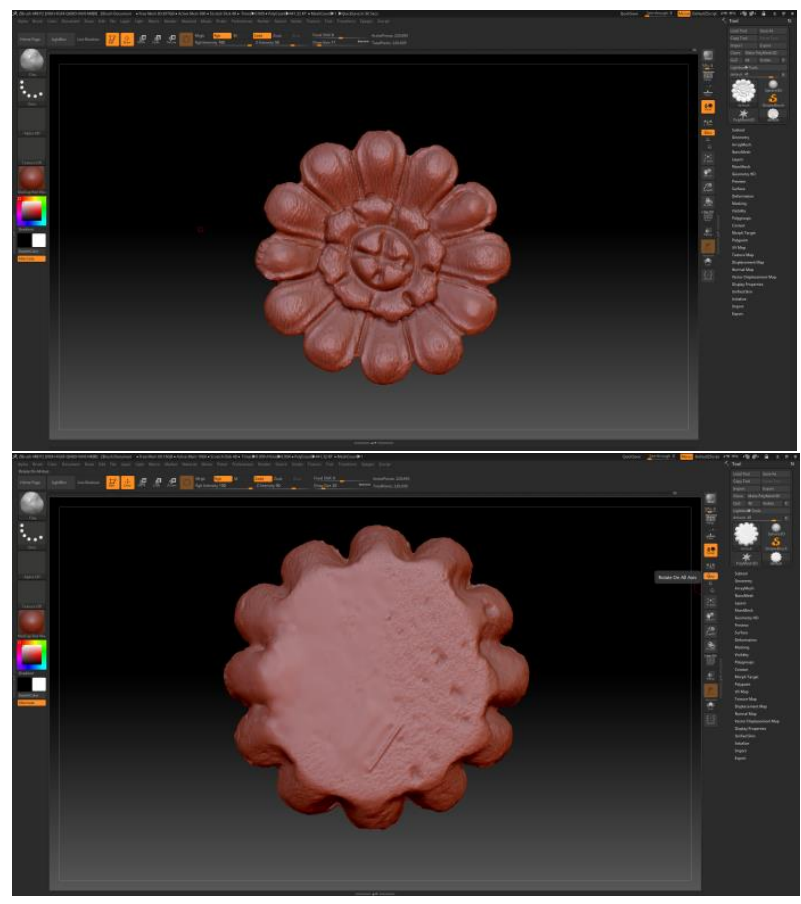

Fig. 4. Restored polygonal model of the rosette ( $\mathrm{a}$ - front side, $\mathrm{b}$ - reverse side).

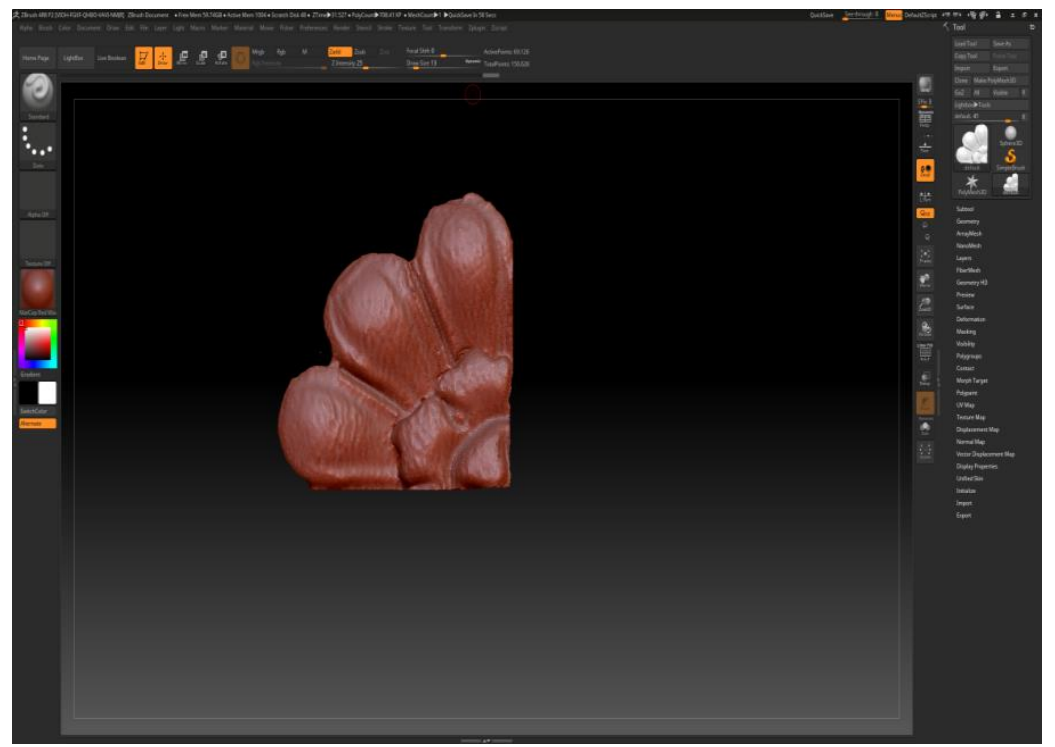

Fig. 5. Highlighted element - a separate polygroup. 


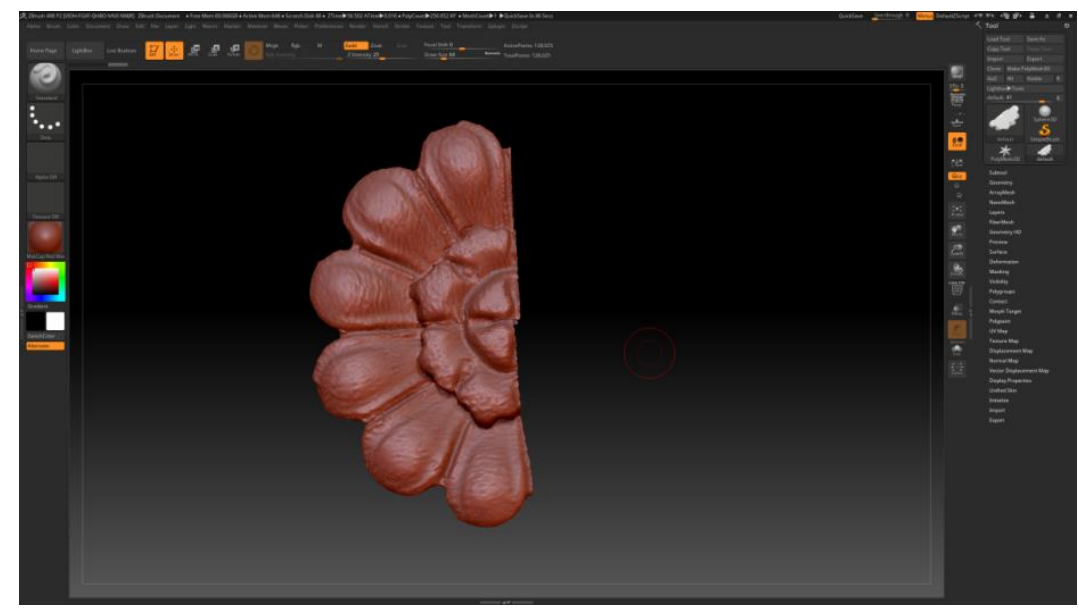

Fig. 6. United polygroup.

a.

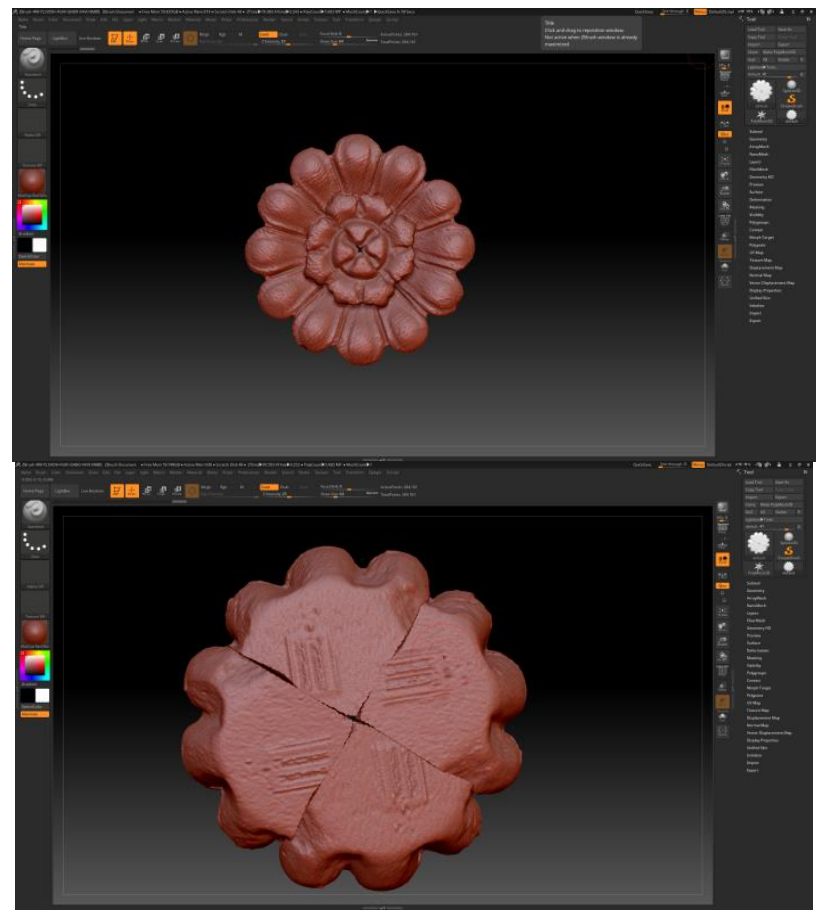

Fig. 7. Complete shape of the rosette ( $\mathrm{a}$ - front side, $\mathrm{b}$ - reverse side).

The final stage of the digital restoration of the rosette is merging the polygroups into a single polygonal mesh. For that purpose, using the Dynamesh feature is recommended, which will produce a new topology of the restored model. Once that operation is done, the new polygonal mesh will consist of uniformly spaced square polygons that are more suitable for sculpting than triangular polygons that were generated as the openings of the selected elements closed. As necessary, we also would 
recommend smoothing over the joints between the united polygroups. The final shape of the rosette after digital restoration is shown in Fig. 8.

a.

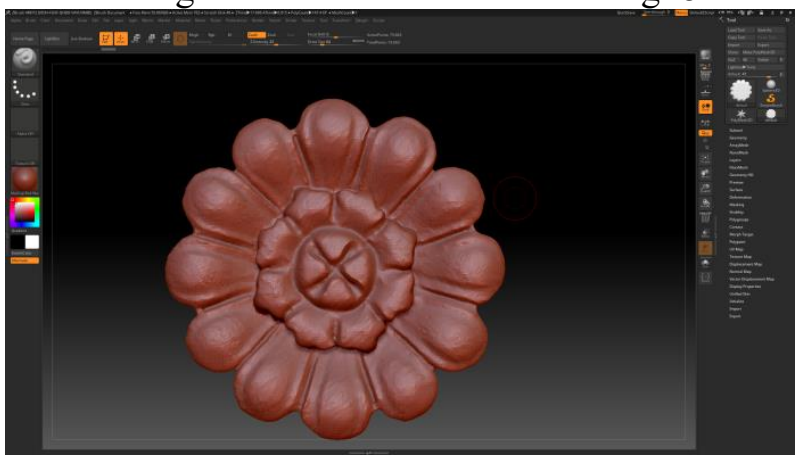

b.

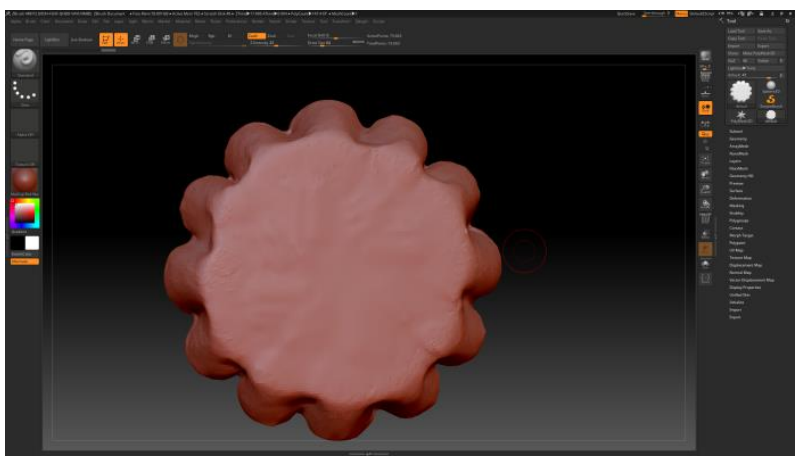

c.

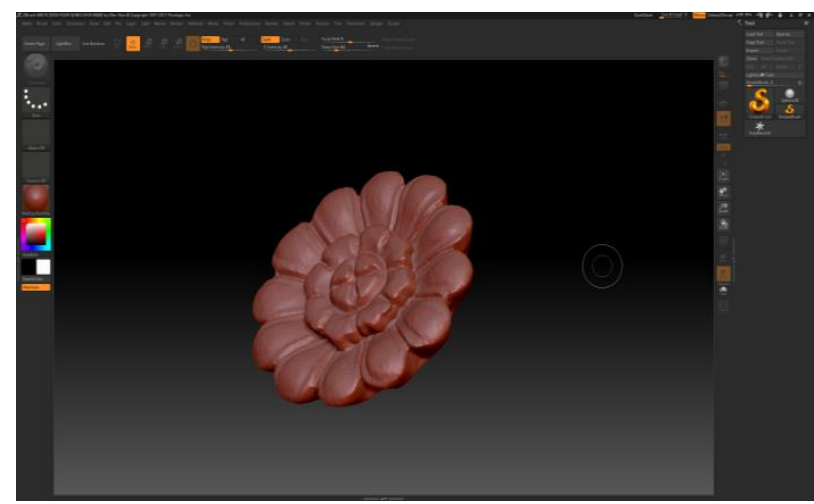

Fig. 8. Final shape of the rosette after the digital restoration $(a-$ front side, $b-$ reverse side, $c-3 D$ image).

Having completed the digital restoration of the rosette, you can decide on the issue of its production. With the conventional process of recreating the recurring items (in our case, rosettes) of architectural molded decor through casting, an authentic, best-preserved part is used as a model. Whereas if there is no authentic extant part usable as a model, one is produced anew. Manual production of the model is performed based on production drawings, commonly full-scale. In this case, the digitally restored model can be used to produce an "underlayer" to be imported into AutoCAD to create production drawings (Fig. 9). 

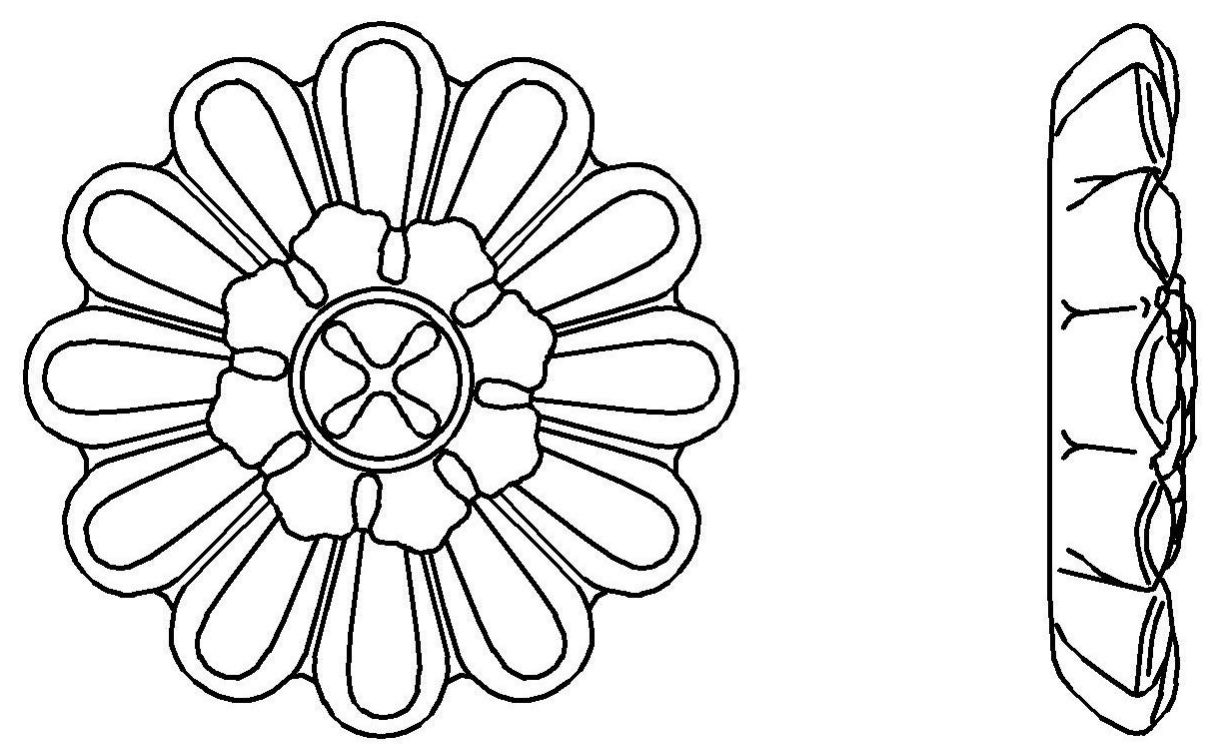

Fig. 9. 2D drawing of the rosette.

The model can also be printed on a 3D printer (beside being manually produced). In this case, the digital three-dimensional model is used to print the rosette on a 3D printer with plastic as the most affordable consumable material. In economically feasible cases, use of a plaster-based 3D printer is recommended to produce the final plaster rosette. In this case, the process of creating the restored rosette is completely free from the so-called human factor because the printer makes no mistakes typical of a restorers' handiwork, which ensures that products comply and are fully identical to the original item (Fig. 10).

\section{Conclusions}

Producing three-dimensional models of architectural decor elements is a complicated process that largely depends on cultural heritage sites. This article describes the methodology of how to restore an architectural decor element (the rosette) using modern 3D technology.

There currently is no universal methodology of restoring architectural decor elements using $3 \mathrm{D}$ technology. Work on every object is a creative process that helps to find different technical solutions, techniques, master some skills and find an optimal technique to produce a high-quality model. For that reason, publishing the results of accumulated positive experience in this field will let experts learn the ways of architectural digitization and virtual digital restoration of decor elements sooner. 


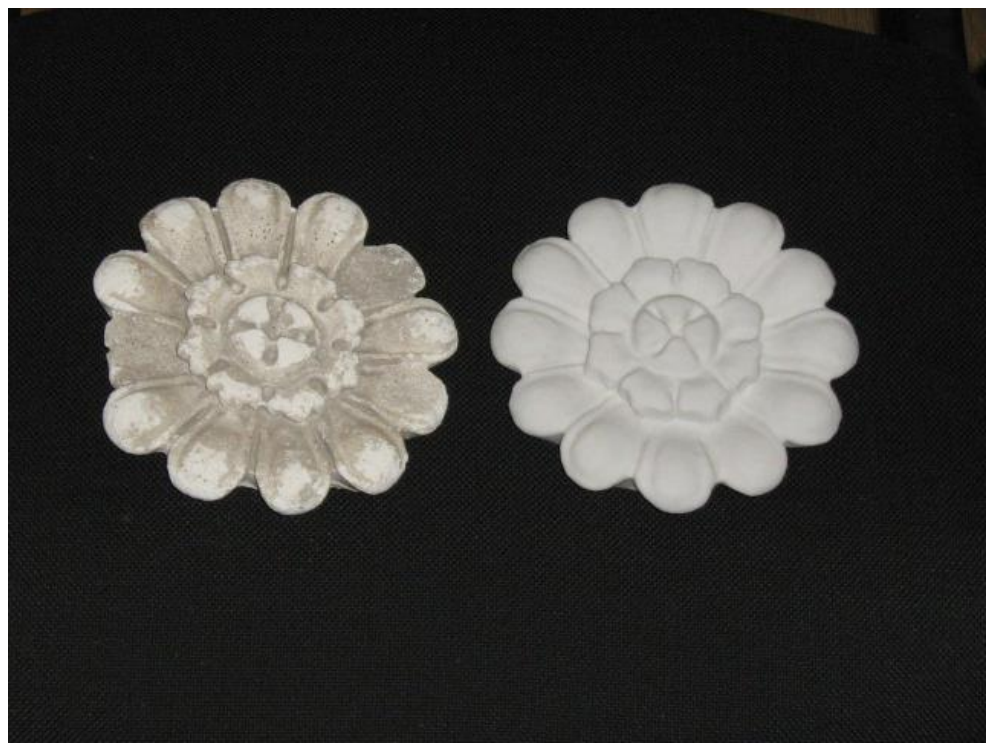

Fig. 10. Initial defective rosette (left) and restored plaster "print" of the rosette (right).

It should be noted that recent trends observed in the field of restoration of architectural monuments that are associated with $3 \mathrm{D}$ techniques resemble the processes that used to occur in the automobile industry in the early 20th century. At that time, the manufacturing of cars was characterized by single-piece production; each part was finished and positioned individually and manually at a place specified by the engineer. This required highly qualified engineers but their performance efficiency was low. Henry Ford implemented conveyor production and the system that later was called "American". It was based on the concept that highly qualified but low-efficient labor of the workers grew to be used in the field of engineering at the designing stage. Thus, the conveyor assembling required the labor of low-qualified workers only.

Now, a similar situation is observed in the field of restoration of architectural monuments due to implementation of innovative 3D scanning and 3D printing techniques. Highly qualified labor of the restorers is growing to be used in the field of computer technology. This trend is quite common but limited by a low rate of 3D printing and a high cost of expendable materials. However, scientists and designers work on those issues, which will surely be fixed soon.

\section{References}

1. S. G. Sheina, D. K. Winnikow, Int.-j. Sci. Sci. 7(3), (2015), http://naukovedenie.ru/PDF/103TVN315.pdf. DOI: 10.15862/103TVN315

2. G. Pavlidis, A. Koutsoudis, F. Arnaoutoglou, V. Tsioukas, C. J. Chamzas, Cult. Herit. 8, 93-98 (2007), DOI: 10.1016/j.culher.2006.10.007

3. G. Pavlidis, D. Tsiafaki, V. Tsioukas, A. Koutsoudis, Int. J. Archit. Comp. 5(2), 222-237 ( 2007), DOI: 10.1260/147807707781514977

4. M. Calin, G. Damian, T. Popescu, R. Manea, B. Erghelegiu,T. Salagean, Agricult. Agricult. Sci. Proc. 6, 421-428 (2015)

https://www.researchgate.net/publication/282335640_3D_Modeling_for_Digital_Preservati on_of_Romanian_Heritage_Monuments 
5. B.T. Andrade, C.M. Mendes, S.J. Oliveira, O.R. Pereira Bellon, L. Silva, J. Cult. Herit. 13, 210-214 (2012), DOI: 10.1016/j.culher.2011.05.003

6. R. Comes, Z. Buna, I. Badiu, J. Anc. Hist. Archeol. 1(2), 236-266, (2014). DOI: http//dx/doi/org/10/14795/j/vli2.55.

https://www.researchgate.net/publication/276926775_CREATION_AND_PRESERVATIO N_OF_DIGITAL_CULTURAL_HERITAGE

7. L. Gomes, O.R. Pereira Bellon, L. Silva, J. Pat. Recog. Let. (2014) DOI: 10.1016/j.patrec.2014.03.023

8. N. Lercari, J. Cult. Herit. 39, 152-165 https://doi.org/10.1016/j.culher.2019.04.005

9. M. Monego, C. Previato, L. Bernardi, A. Menin, V. Achilli, J. Archaeol. Sci. Reports, 24, 445-462 (2019), https://doi.org/10.1016/j.jasrep.2019.02.009

10. N. Yastikli, J. Cult. Herit. 8, 423-427 (2007) DOI: 10.1016/j.culher.2007.06.003

11. A. Campiani, A. Lingle, N. Lercari, J. Cult. Herit. 39, 166-176 (2019), https://escholarship.org/uc/item/33p4q5cr

12. A. Rizzi, F. Voltolini, S. Girardi, L. Gonzo, F. Remondino, XXI International CIPA Symposium, Athens, Greece (2007). https://www.researchgate.net/publication/228645992_Digital_preservation_documentation _and_analysis_of_paintings_monuments_and_large_cultural_heritage_with_infrared_techn ology_digital_cameras_and_range

13. C. Măruţoiu, I. Bratu, M. I. Ţiplic, V. C. Măruţoiu, A. Hernanz, , J. Archaeol. Sci. Reports, 19, 148-154 (2018), DOI: 10.1016/j.jasrep.2018.02.044

14. I. Siebke, L. Campana, M. Ramstein, A. Furtwängler, A. Hafner, S. Lösch, Dig. App. Archaeol. Cult. Herit. 10, (2018), DOI: 10.1016/j.daach.2018.

15. A. Grün, F. Remondino, L. Zhang, Photogram. Rec. 19(107), 177-199 (2004) https://www.researchgate.net/publication/227635047_Photogrammetric_Reconstruction_of _the_Great_Buddha_of_Bamiyan_Afghanistan

16. S. F. El-Hakim, J. A. Beraldin, M. Picard, G. Godin, 2004IEEE Comp. Graph. App. 24(3), 21-29 (2004)

https://www.researchgate.net/publication/3209199_Detailed_3D_reconstruction_of_largescale_heritage_sites_with_integrated_techniques

17. F. Remondino, S. El-Hakim, Photogram. Rec. 21(115), 269-291 (2006)

https://www.researchgate.net/publication/227786426_Image-

based_3D_Modelling_A_Review

18. Kersten, XXth ISPRS congress, (2004)

https://www.researchgate.net/publication/237771322_3D_ACQUISITION_MODELLING_ AND_VISUALIZATION_OF_NORTH_GERMAN_CASTLES_BY_DIGITAL_ARCHIT ECTURAL_PHOTOGRAMMETRY

19. I. Aicardi, F. Chiabrando, A. M. Lingua, F. Noardo, J. Cult. Herit. 32, 257-266 (2018) doi:10.1016/j.culher.2017.11.006

20. Yu. V. Pukharenko, S. G. Golovina, V. A. Norin, Yu. V. Sokol, Civ. Engin. Bull. 5(70), 128-135 (2018) DOI 10.23968/1999-5571-2018-15-5-128-135 